\title{
Manovolumetry: a new method for investigation of anorectal function
}

\author{
S ÅKERVALL, S FASTH, S NORDGREN, T ÖRESLAND, AND L HULTÉN \\ From the Department of Surgery II, University of Göteborg, Sahlgrenska sjukhuset, S-413 45 Göteborg, \\ Sweden
}

SUMmARY A new technique for manovolumetric investigation of rectoanal function allowing for simultaneous recording of rectal volume, anal pressure and external sphincter EMG in response to graded rectal distension was developed. Distension pressure was generated by a water column between two reservoirs. Volume was recorded as shifts of water between the reservoirs. Anal pressure was recorded with a cylindrical balloon and electromyographic activity of the external sphincter by means of a needle electrode. It could be shown that although reduction of preset pressure was minimal, this factor had to be taken into account when rectal compliance is high. The position of the patients during the investigation has to be defined, because rectal volume changed with body position. Pull through studies of anal pressure indicated low sensitivity to displacement of the cylindrical anal probe. A pressure adaptation to the anal probe during eight minutes was noted. Representative recordings of the anorectal response to different isobaric pressures are presented. The present system offers new possibilities for investigation of rectoanal physiology in man.

Anal continence and the act of defecation depend on a normal function of the rectum and anus and include a centrally integrated action of the autonomic and the somatic nerves. ${ }^{\prime}$ Distension of the rectum elicits a contraction of the bowel and an internal anal sphincter relaxation. Provided that there is a concomitant relaxation of the voluntarily controlled external sphincter the bowel is thereby emptied. Studies in animals have shown evidence that the pelvic nerves also convey relaxatory fibres to the rectum which probably play an important role in the reception and storage of faeces and gas. ${ }^{2}$ These findings were made possible by using an 'isobaric volume recording' which had earlier been extensively used in studies of the reservoir function of the stomach and urinary bladder in animals and man..$^{3-5}$

The knowledge of the integrated control of rectoanal function in man is somewhat sparse. This is at least partly explained by the fact that most methods have been designed mainly to study the anal sphincters. ${ }^{-12}$ Consequently the part played by the rectum in continence and defecation is less well

Address for correspondence: S Ăkervall, MD, Department of Surgery II, Sahlgrenska sjukhuset, S-413 45 Göteborg, Sweden.

Received for publication 6 November 1987 understood. The aim of the present study was therefore to design a method for rectoanal manometry allowing for a detailed assessment not only of the anal sphincter function but also of the dynamic functional performance of the rectum as regards storage and expulsive function and the rectal interaction with the sphincter muscles.

\section{Methods}

TECHNICAL DESCRIPTION

The rectoanal manovolumetry device consists of three main units, one reflecting rectal volume, also providing continuous rectal distension at constant pressure, a second unit recording anal pressure, and a third monitoring EMG signals from the external anal sphincter.

\section{Rectal volumetry and distension}

The unit for rectal volumetry and distension appears in Figure 1. A cylindrical acrylic vessel open to air and with a surface area of $150 \mathrm{~cm}^{2}$ serves as a water reservoir. It is suspended on a force displacement transducer (Grass FT 10D), for continuous weight recording and is connected via a non-distensible tube 


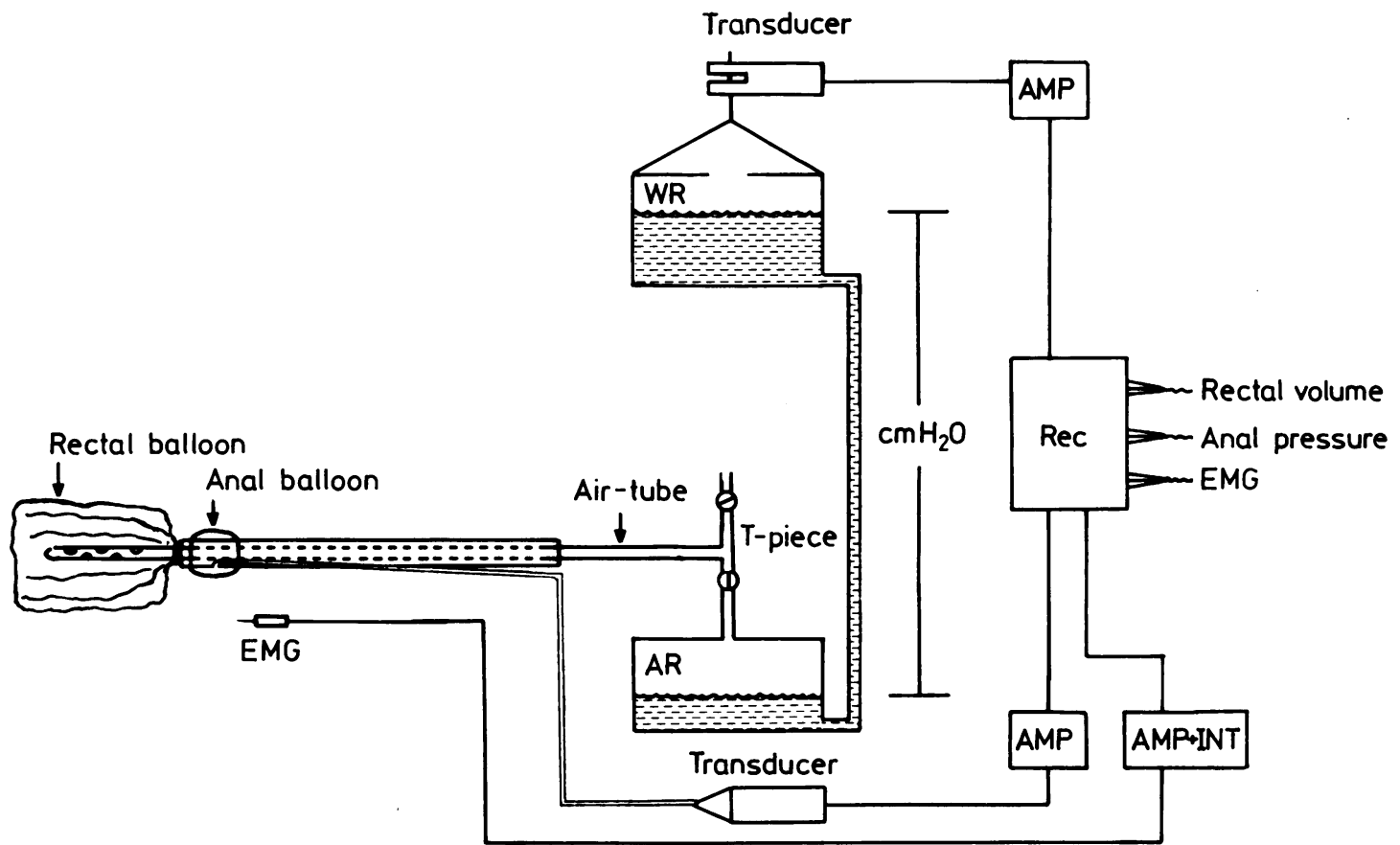

Fig. 1 Diagrammatic representation of the investigational apparatus. For explanation-see text $(A M P=a m p l i f i e r$, $I N T=$ integrator, $R E C=$ recorder, $W R=$ water reservoir, $A R=$ air reservoir).

(id $12 \mathrm{~mm}$, length $100 \mathrm{~cm}$ ) to an air reservoir with a similar surface area and a volume of $600 \mathrm{ml}$. The air reservoir is connected, through a T-piece, to a rectal balloon by means of a non-distensible plastic tube ( 18 $\mathrm{Ch}$, id $4 \mathrm{~mm}$, the air tube). The system is closed by clamping the air tube. The rectal balloon is a high compliance, thin wall $(0.025 \mathrm{~mm})$ disposable polyethelene bag which is hermetically tied to the air tube. The balloon has a length of $120 \mathrm{~mm}$ when deflated and $100 \mathrm{~mm}$ fully inflated. Its maximum volume is $500 \mathrm{ml}$.

When the water reservoir is raised above the air reservoir a pressure is generated in the air compartment of the air reservoir. This pressure is equal to the difference of level between the surfaces of water in the two reservoirs and is conveniently expressed in $\mathrm{cm}_{2} \mathrm{O}$ (conversion factor $0.098 \mathrm{k} \mathrm{Pa}$ ). When the air tube is opened, water flows into the air reservoir and air is expelled into the rectal balloon. The signal of concomitant weight change of the water reservoir, reflecting the volume of air in the rectal balloon $(1 \mathrm{~g}$ water is set equal to $1 \mathrm{ml}$ air, see below) is amplified (Grass, model 7 DAG) and recorded on a Grass Polygraph (model 7D). Reading accuracy of the volume registration is $2 \mathrm{ml}$.

\section{Recording of anal pressure}

A disposable cuffed endotracheal tube (Malinckrodt, no 7 , od $10 \mathrm{~mm}$, cuff length $31 \mathrm{~mm}$ ), is used for recording anal pressure. The cuff of the tube and its tubing is filled with water and connected to a Statham pressure transducer (P $23 \mathrm{AC}$ ) for continuous anal pressure recording. The endotracheal tube is thread on to the air tube of the rectal balloon. This system allows for simultaneous and continuous recording of changes in anal pressure and rectal volume on graded rectal distension. Anal pressure is recorded on the polygraph. Reading accuracy of the pressure registration is $2 \mathrm{~mm} \mathrm{Hg}$.

\section{Electromyographic recording}

A concentric needle electrode (DISA No 13 L50, length $30 \mathrm{~mm}$, od $0.45 \mathrm{~mm}$ ) is introduced into the subcutaneous portion of the external anal sphincter. The electrical signals are passed through a preamplifier and integrator (Grass, model 7P 3C). After integration (spikes/0.5 s) the signal is amplified (Grass, model 7DAG) and recorded on the polygraph.

\section{INVESTIGATIONAL PROCEDURE}

Fifteen healthy volunteers of both sexes with a mean age of 30 years (range 23-43) and without a history or signs of anorectal disease were used for methodological analysis. The subjects were asked to empty the rectum and bladder before the investigation. No 
bowel preparation was used and written informed consent to participation was obtained. The study was approved by the Ethical Committee of the University of Göteborg.

The investigation was conducted with the subject lying comfortably either in the supine or in the left lateral position. The rectal balloon was inserted and placed in the rectal ampulla by use of a sigmoidoscope. Inflation of air was avoided. By using the air tube as a guide, the anal probe was then introduced through the anus, and placed in the anal canal. The anal probe was secured to the buttocks with tape or held in position by the investigator. The needle electrode was inserted into the external anal sphincter $10-15 \mathrm{~mm}$ posterolateral to the anal verge after skin preparation with chlorhexidine in alcohol $(0.5 \%)$. A preliminary inflation of the rectal balloon with a pressure of $40 \mathrm{~cm} \mathrm{H}_{2} \mathrm{O}$ was performed to allow the rectal balloon to unfold. Inflation was stopped by clamping the air tube and rectal distension pressure released by opening the T-piece (Fig. 1). The investigation was carried out as a series of distensions with $5 \mathrm{~cm} \mathrm{H}_{2} \mathrm{O}$ increments starting at $5 \mathrm{~cm} \mathrm{H}_{2} \mathrm{O}$ up to 60 $\mathrm{cm} \mathrm{H}_{2} \mathrm{O}$ and each distension lasting one or two minutes. After each distension the rectal balloon was emptied and water returned to the water reservoir. During the initial phase of each distension subjects were told to report and classify any sensation.

\section{Results}

\section{CRITICAL ANALYSIS OF THE METHOD}

RECTAL VOLUMETRY AND DISTENSION

Effects of reduction of pre-set distension pressure and rectal compliance on recorded volume

Despite the large cross-sectional area of the reservoirs displacement of water from the water reservoir to the air reservoir causes a reduction of the difference between the water levels and hence a reduction of the preset pressure. For every $75 \mathrm{ml}$ water escaping from the water reservoir pressure is reduced by $1 \mathrm{~cm} \mathrm{H}_{2} \mathrm{O}$. The reservoir compliance is therefore $75 \mathrm{ml} / \mathrm{cm} \mathrm{H}_{2} \mathrm{O}$. The reduced distension pressure will cause a rectal volume increase that is smaller than the originally preset pressure would give. The error of rectal volume is not systematic

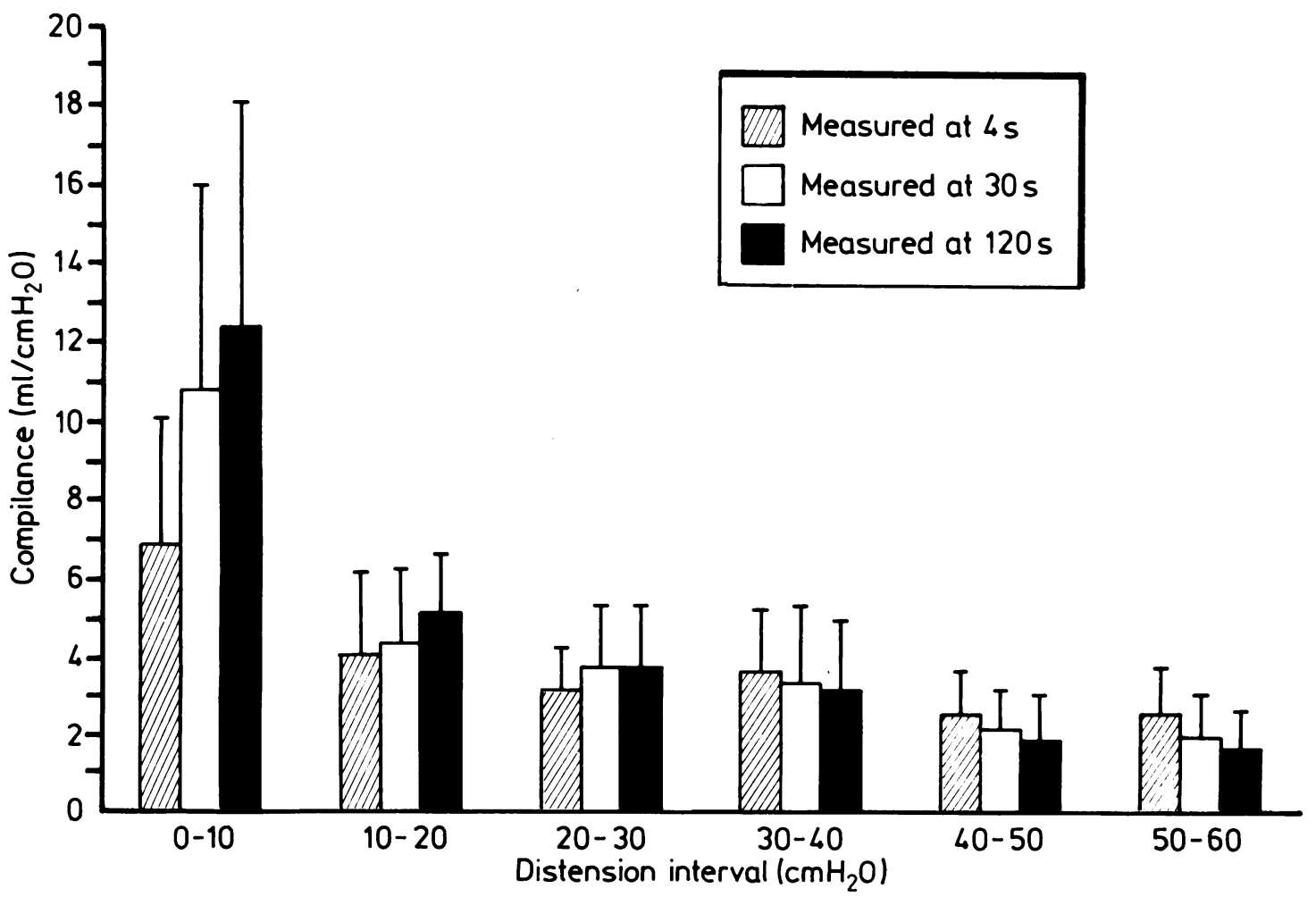

Fig. 2 Rectal compliance, at different distension pressure intervals after 4, 30, and 120 sec in the left lateral position /mean $(S D) n=14]$. 


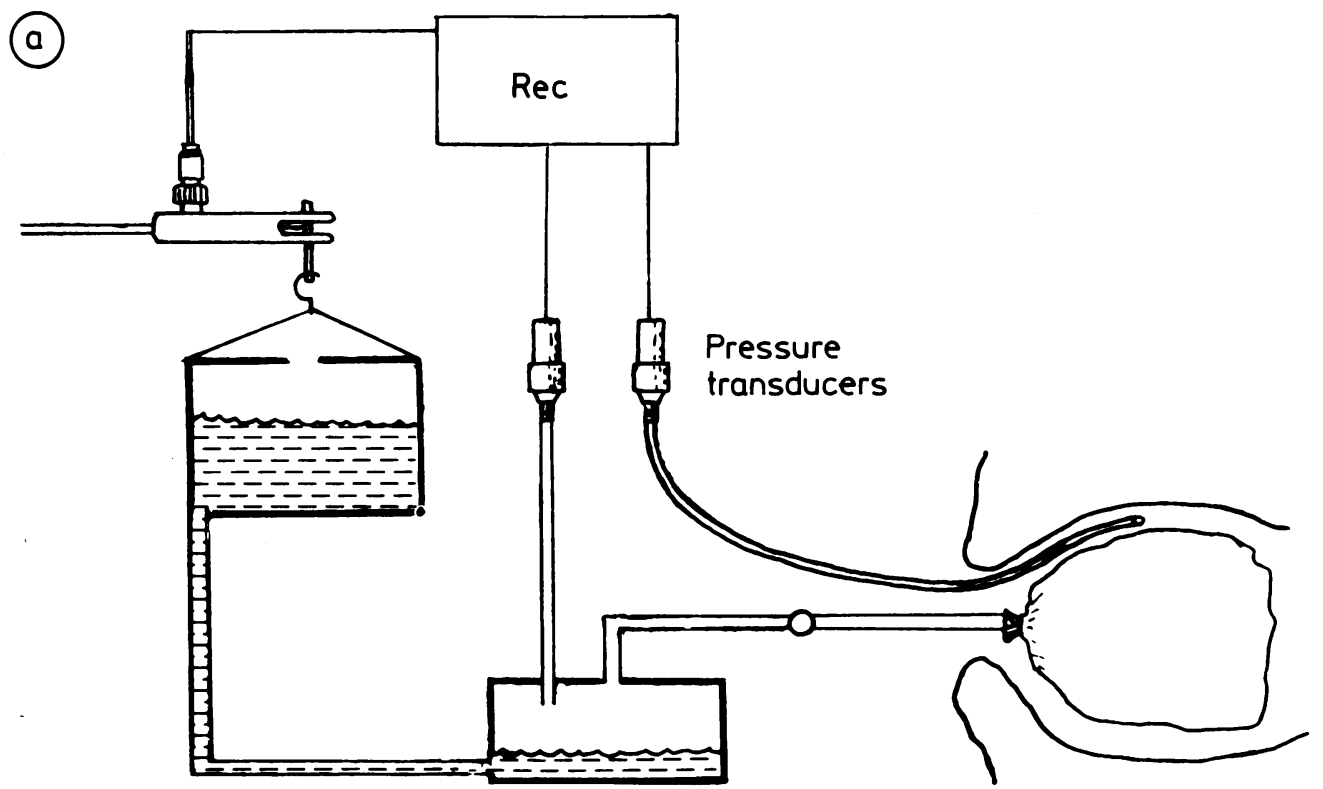

Fig. 3 (a) Experimental device for investigation of early pressure and volume changes on rectal distension. (b) Early pressure and volume events following opening of the air tube. Distension pressure $=40 \mathrm{~cm} \mathrm{H}_{2} \mathrm{O}$ (mean, $\left.\mathrm{SEM}, n=5\right)$.

(b)

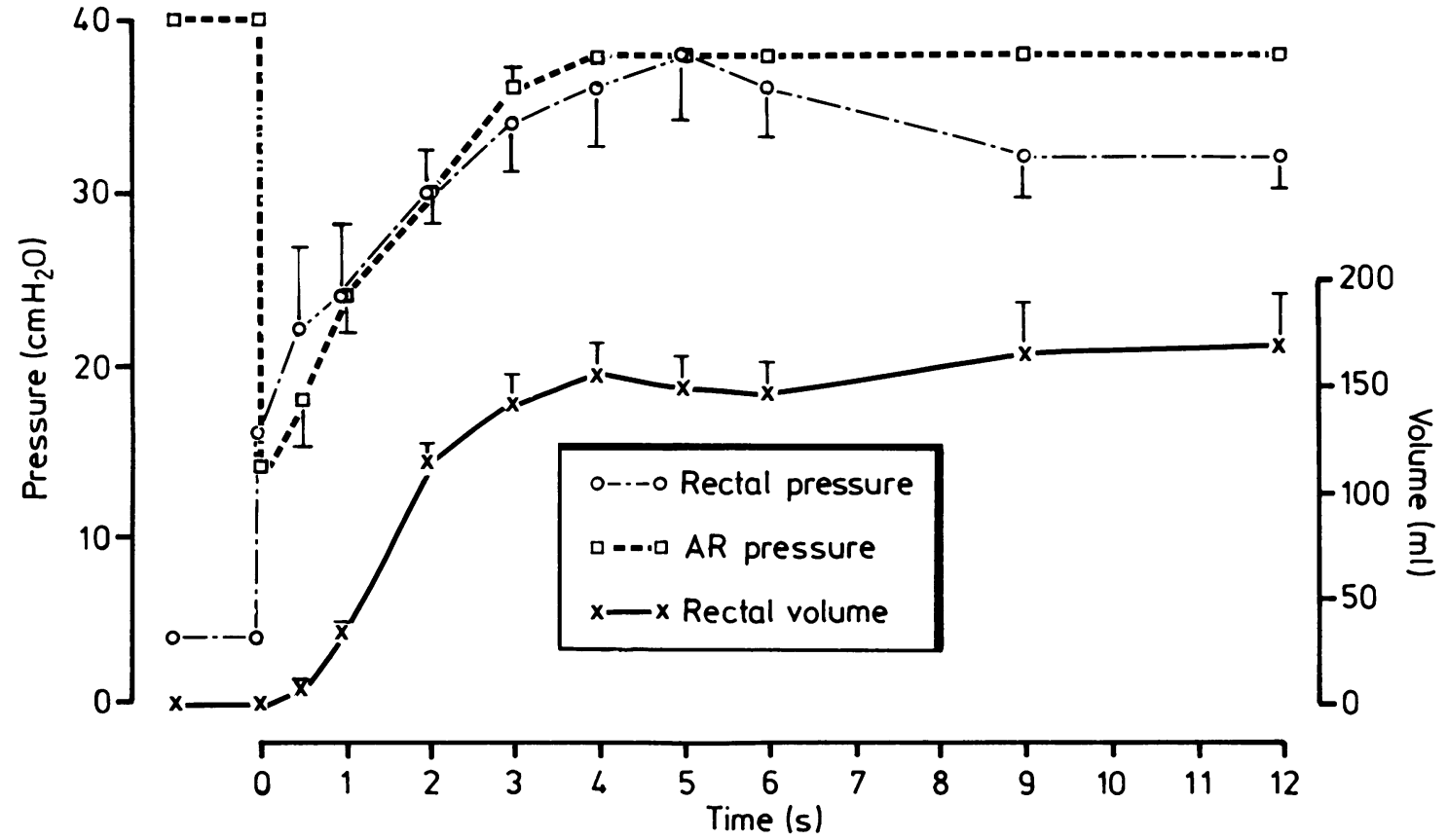

because rectal compliance varies between individuals and in different pressure intervals.

Rectal compliance - rectal volume increase per unit pressure increase - was investigated in 14 patients in order to assess the significance of the reduction of preset pressure. Six pressure intervals were studied at 4,30 , and $120 \mathrm{~s}$ of distension (Fig. 2). It could be shown that rectal volume is not a linear function of 
Table Rectal compliance and relative volume error $(n=14)$

Distension pressure interval $\left(\mathrm{cmH}_{2} \mathrm{O}\right)$

Rectal compliance

$\left(\mathrm{ml} / \mathrm{cmH}_{2} \mathrm{O}\right)$

\begin{tabular}{lccc} 
& $5-10$ & $15-40$ & $40-60$ \\
\cline { 2 - 4 } Mean & 11.8 & 3.7 & 1.7 \\
Range & $3.2-23.2$ & $1.7-6.2$ & $0.5-4.1$
\end{tabular}

Volume error

(\%)

Mean

4.8

$2 \cdot 2$

Range $\quad 4.2-30.2 \quad 2.2-8.0 \quad 0.7-5.3$

imposed pressure. Rectal compliance varied with time and pressure interval and was greatest after long term distension and at low pressure intervals. After $120 \mathrm{~s}$ distension the compliance reached $12.3 \mathrm{ml} / \mathrm{cm}$ $\mathrm{H}_{2} \mathrm{O}$ in the pressure interval $0-10 \mathrm{~cm} \mathrm{H}_{2} \mathrm{O}$. The volume error, due to the reservoir compliance $(75 \mathrm{ml} /$ $\mathrm{cm} \mathrm{H}_{2} \mathrm{O}$ ) and rectal compliance was calculated for three pressure intervals (Table). Mean volume error was $15.3 \%$ in the interval $5-10 \mathrm{~cm} \mathrm{H}_{2} \mathrm{O}$ and less than $5 \%$ at higher pressures.

\section{Effects of the physical properties of the device on} recorded volume

Another error of recorded volume might be induced by inertia of the water in the reservoirs and in the tubings, by resonance of the water column and the air compartment and by temperature changes of the gas in the rectal balloon.

Details of the relation between dynamic rectal volume recording and the actual expansion of the balloon are shown in Figure 3a.

On unclamping the air tube, air instantaneously entered the rectal balloon which was recorded as an acute pressure rise in the rectum (Fig. 3b). Because of the inertia of the water column this initial short lasting inflation was not recorded as a weight change of the water reservoir. The time to reach a stable distension pressure (recorded from the air reservoir) was consistently less than $4 \mathrm{~s}$ (Fig. 3b). When the stable distension pressure level is reached the volume record reflects the true amount of air in the rectal balloon.

The dynamic response characteristics of the volumetric system were assessed in an in vitro model using imposed sinusoidal waves from a sine-wave generator (Exact, model 508, Log Sweep Function Generator). The natural frequency of the volumetric system was found to be $0.4 \mathrm{~Hz}$. The phase lag at $0 \cdot 15 \mathrm{~Hz}$, which corresponds to the highest frequency recorded from the rectum, ${ }^{13}$ was $0.5 \mathrm{~s}$. This indicates that pressure changes recorded from the anal canal, by the anal probe (instantaneous reaction) ${ }^{14}$ are observed approximately half a second ahead of simultaneous volume events recorded from the rectum.

The expansion of the gas in the air reservoir caused by loss of the preset pressure is approximately $0 \cdot 1 \% / \mathrm{cm}_{2} \mathrm{O}$ and is partly counteracted by compression of the air in the air tube distal to the clamp. This causes a negligible deviation from the assumption that loss of $1 \mathrm{~g}$ water from the water reservoir equals expansion of the rectal balloon with $1 \mathrm{ml}$ air. The volume error caused by temperature changes of the gas in the rectal balloon was studied in a climate chamber and was found to be consistently less than $2 \mathrm{ml}$. A minor deviation from a systematic error can be expected since a small volume of air is heated faster than a large volume. For instance $100 \mathrm{ml}$ air in the rectal balloon was calculated by Charles' law to expand $1.3 \mathrm{ml}$ when exposed to $37^{\circ} \mathrm{C}$ during one minute whereas $300 \mathrm{ml}$ expanded $3.6 \mathrm{ml}$ under the same circumstance. The deviation from a systematic error was thus only $0.3 \mathrm{ml}$.

\section{Effect of body position}

The effect of body position on rectal volume record during graded distension was investigated in nine volunteers. The subjects were investigated in the left lateral position and in the supine position on separate occasions. Rectal volume after $60 \mathrm{~s}$ of graded distension was recorded (Fig. 4). At pressures within the range of $5-40 \mathrm{~cm} \mathrm{H}_{2} \mathrm{O}$ the pressure/volume curve in the supine position was displaced $10-15 \mathrm{~cm} \mathrm{H}_{2} \mathrm{O}$ to the right of the records from patients in the left lateral position.

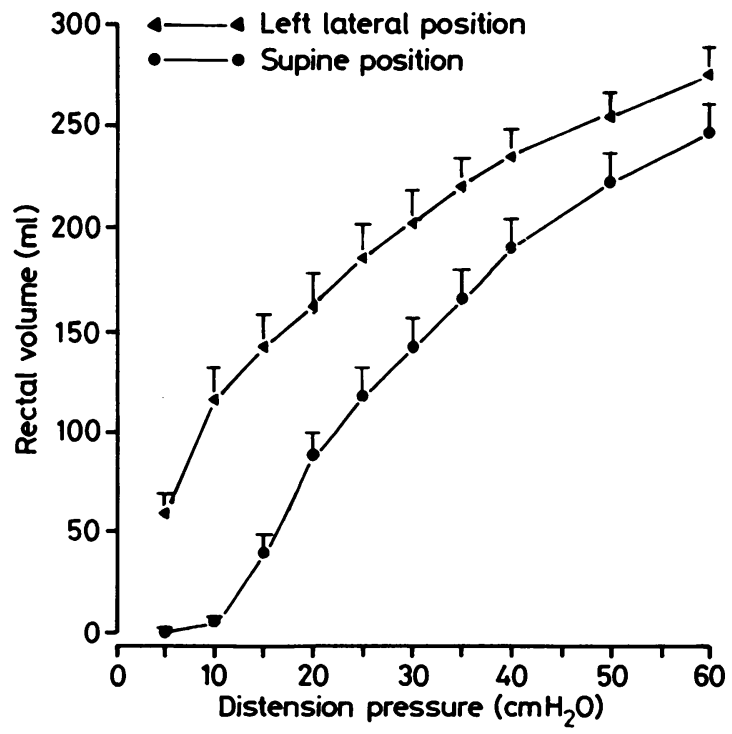

Fig. 4 Rectal volume (at $60 \mathrm{sec}$ ) in the left lateral and supine position as a function of distension pressure [mean (SE) $n=14]$. Differences of volume at each pressure level were statistically significant $(p<0 \cdot 05$, Student's t test). 


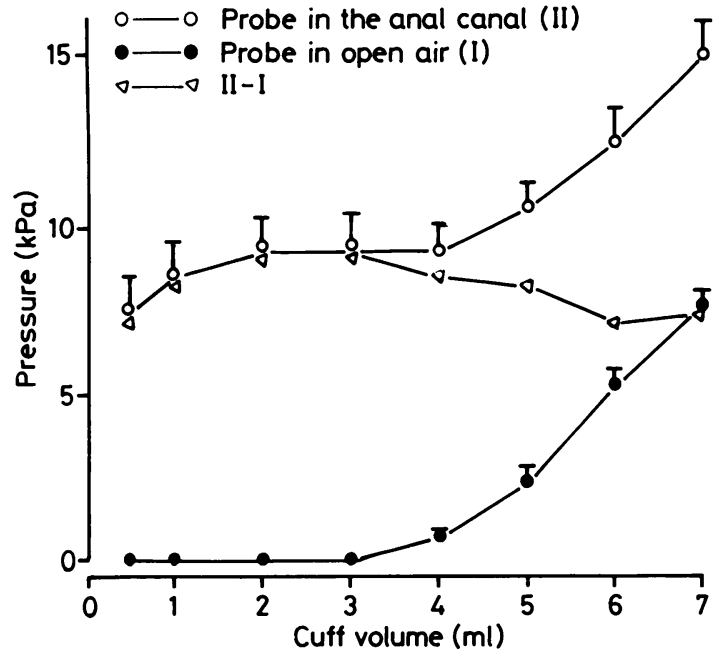

Fig. 5 Anal cuff pressure versus cuff volume in situ and in open air [mean (SE) $n=5]$.

RECORDING OF ANAL PRESSURE

In order to test the reproducibility of anal pressure recordings the following methodological analysis was carried out.
Effects of incremental filling of the anal probe

To study the influence of graded filling on the pressure measured from the anal canal/anal probe pressure was measured during intermittent infusion of water $(0-7 \mathrm{ml}, 1 \mathrm{ml} / \mathrm{min})$ in five subjects. This procedure was repeated with the anal probe in open air. As is shown in Figure 5, a significant contribution to the recorded pressure from the walls of the anal probe occurred when filling exceeded $3 \mathrm{ml}$. It was therefore decided to use $2 \mathrm{ml}$ water in the anal cuff.

Position of the anal probe

The importance of the position of the anal probe on the anal pressure record was studied by a pullthrough procedure. The anal probe was introduced into the rectum and withdrawn at a constant speed of $3.3 \mathrm{~mm} / \mathrm{min}$ through the anal canal during continuous recording of cuff pressure. Similar experiments were performed with a thin open tip catheter $($ od $2 \mathrm{~mm}$, id $1 \mathrm{~mm})$ with a side port $(2 \times 1 \mathrm{~mm})$ and with a large bore open-tip catheter (od $10 \mathrm{~mm}$, port size $2 \times 1$ $\mathrm{mm})$. As is shown in Figure 6 a high pressure zone in the anal canal was recorded by the probe and by the open-tip catheters with a pressure plateau that was 15-20 mm long. A standardised position of the anal

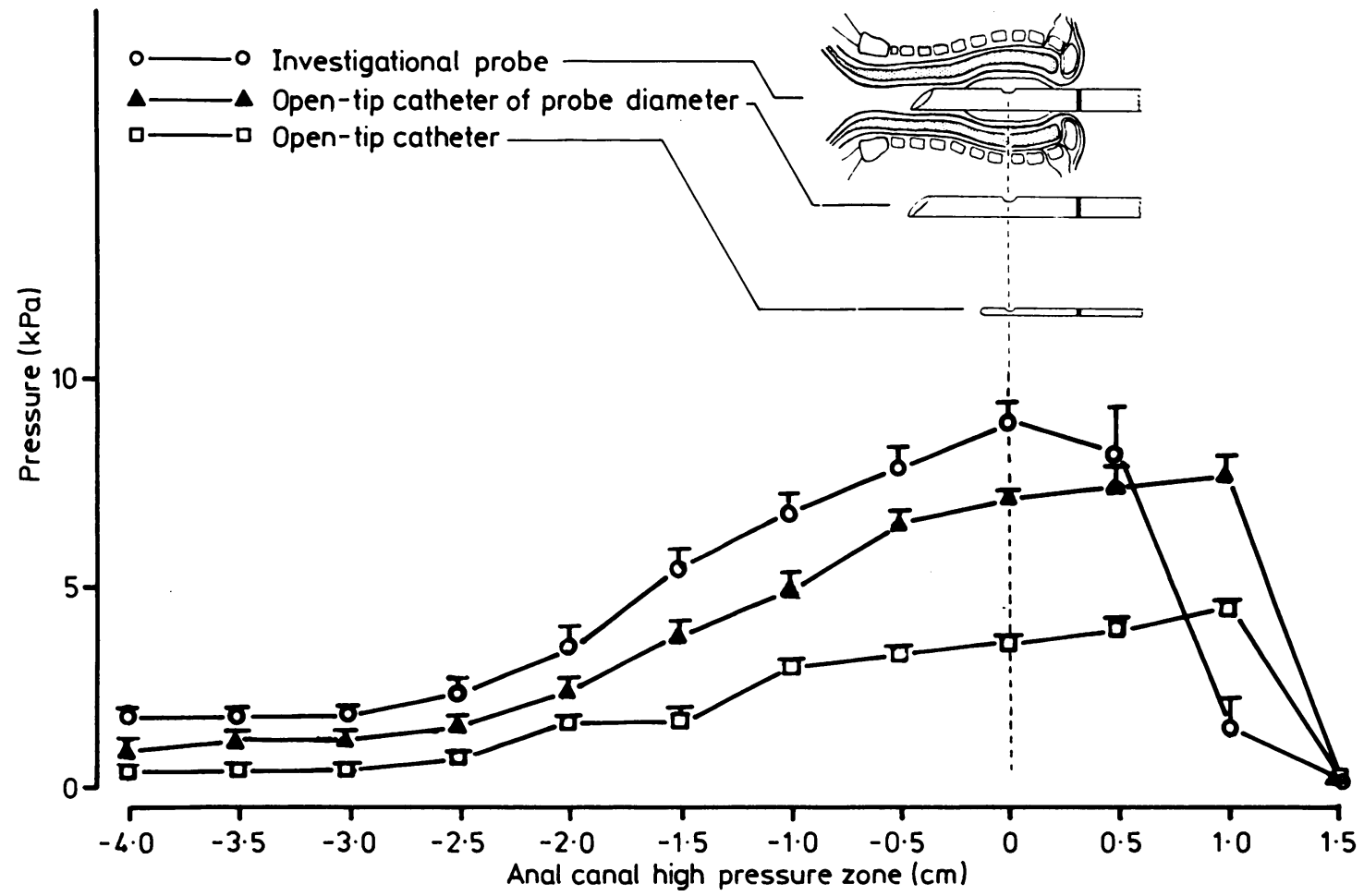

Fig. 6 Anal pressure profiles recorded with three different probes (open tip catheter $0=2 \mathrm{~mm}, 0=10 \mathrm{~mm}$ and anal probe [mean (SE) $n=5$ ]. 


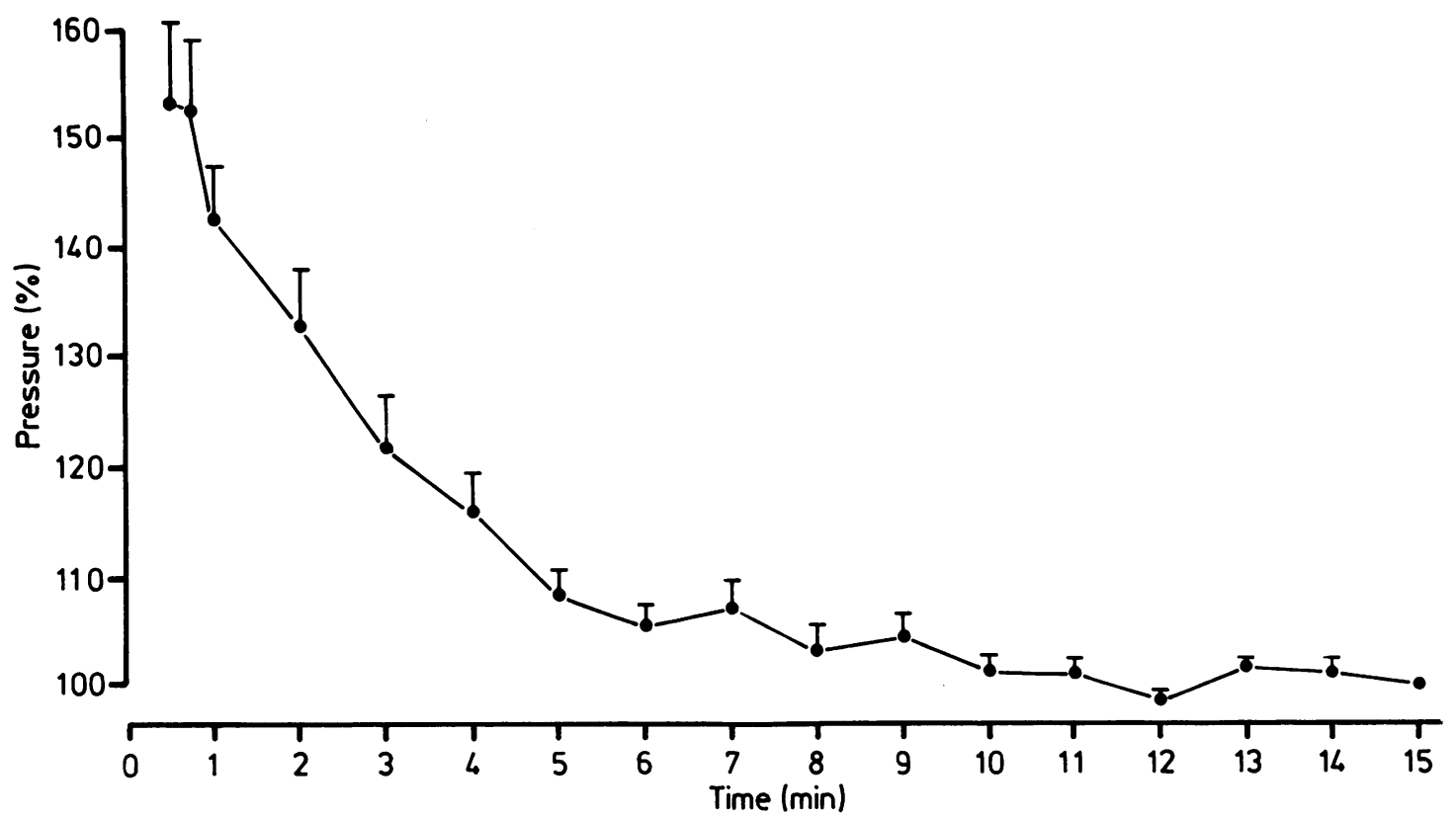

Fig. 7 Pressure adaptation to the anal probe expressed as relative anal pressure versus time [anal pressure at 15 min $=100 \%$, mean (SE) $n=16]$.

probe was selected from this experiment. By placing the probe so that the subcutaneous portion of the external sphincter just closed over the lower end of the cuff (position ' $0 \mathrm{~cm}$ ', Fig. 6), minimal pressure changes was recorded for a dislocation $\pm 0.5 \mathrm{~cm}$.

\section{Anal adaptation to the probe}

To elucidate possible adaptation of the anal muscles to the anal probe with time, the probe was positioned in the anal canal in 15 control subjects as defined above. Anal pressure was continuously recorded during 15 min after the introduction. Figure 7 shows that there was a significant drop in anal pressure during the first five minutes, but after eight minutes no further pressure decrease was noted. Anal pressure decreased $24 \pm 11 \%$ between one and five minutes after introduction of the probe.

\section{REPRESENTATIVE REGISTRATION OF THE}

ANORECTAL RESPONSE TO RECTAL DISTENSION Simultaneous recordings of rectal volume, anal pressure and external sphincter EMG on rectal distension are shown in Figure 8. Within five seconds the initial rapid volume expansion was interrupted and at high distension pressure $\left(40 \mathrm{~cm} \mathrm{H}_{2} \mathrm{O}\right)$ reversed to a decrease of rectal volume lasting 10-15 s. Subsequently a slow, gradually retarding volume increase was noted. After one minute the volume was virtually stable. The rectal distension also elicited a reduction of anal pressure which at $40 \mathrm{~cm} \mathrm{H}_{2} \mathrm{O}$ was preceded by a shortlasting increase appearing simultaneously with an initial increased EMG activity. At $10 \mathrm{~cm} \mathrm{H}_{2} \mathrm{O}$ distension anal pressure returned to resting level during the distension whereas the pressure remained reduced during distension with $40 \mathrm{~cm} \mathrm{H}_{2} \mathrm{O}$. Concomitant with a rapid return to resting level at cessation of the distension there was a transient increase of EMG activity.

\section{Discussion}

\section{RECTAL VOLUMETRY}

In the present report a method is introduced for clinical and experimental rectoanal manometry, which is based on a principle different from those presently used. The main difference is that the present system allows for simultaneous recording of rectal volume and anal pressure in response to rectal distension with a preset pressure. This is accomplished by means of a high compliance $(75 \mathrm{ml} / \mathrm{cm}$ $\mathrm{H}_{2} \mathrm{O}$ ) plethysmographic volume recording system which causes small changes of the preset pressure for shifts of proportionally large volumes of fluid ('isobaric volume recording'). Hightower et al ${ }^{15}$ devised a method where pressure variations from a preset level were measured. Although this shows similarities with the present method it remains a pressure recording technique, and isobaric conditions do not prevail. The basic concept of the isobaric volume recording used in the present method was 

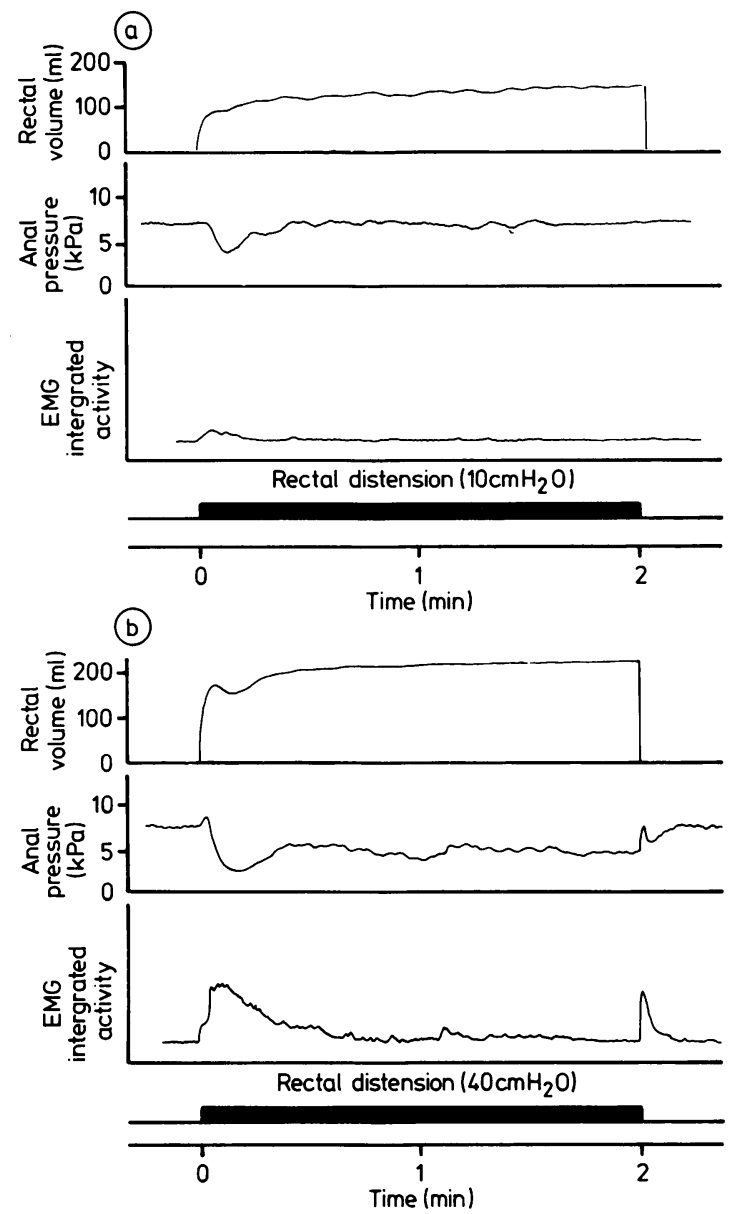

Fig. 8 Representative registrations of rectoanal response to isotonic distension at 10 and $40 \mathrm{~cm} \mathrm{H}_{2} \mathrm{O}$ respectively.

developed by Martinsson in 1965 in an experimental study of gastric motility ${ }^{4}$ and by Sundin and Carlsson in 1972 in an investigation of feline urinary bladder motility. ${ }^{5}$ In these studies fluid was used for volumetry and distension which may be unsatisfactory because of resistance to flow but appropriate when small fluid shifts are recorded. The present method uses a water column for creating pressure and air as distension medium, a combination that is attained by adding an air reservoir to the distension system (Fig. 1). This type of system is similar to that developed by Jahnberg et al in $1975 .{ }^{3}$ Resistance to flow is thereby minimised and so are also the effects of fluid mass and temperature on the rectal wall.

In standard methods for rectoanal manometry rectal distension is accomplished by predetermined, usually incremental, filling of a latex rectal balloon with air or fluid. Rectal pressure and motility is therefore not directly available as a pressure may be generated in the walls of the balloon. Ihre ${ }^{y}$ circumvented this limitation by determinating 'true' rectal pressure for different volumes. This was accomplished by subtracting balloon pressure in open air from the balloon pressure in the rectum. This calculation eliminated the pressure generated by the tension in the balloon. A similar subtraction method was used by another group in studies of elastic properties of the rectal wall. ${ }^{16}$ This method for rectal volume recording appears unreliable and inexact for a dynamic volume record as balloon tension changes with volume and hysteresis cannot be excluded. In the present system no tension is created in the walls of the balloon in the interval $0-500 \mathrm{ml}$ and the distension pressure is transferred entirely to the rectal wall. This is in accordance with the objectives of Hightower et $a l^{\text {15 }}$ who purposely changed the 'rigidity' of the sensing balloon to mimic the physical properties of the intestinal contents. Another advantage to the present system is that it is more sensitive to pressure changes than the conventional isometric pressure recording technique.

A disadvantage to the present system is that the reduction of pressure induced by shifts of water between the two reservoirs tends to decrease the preset distension pressure and rectal volume is therefore consistently underestimated. This error is not systematic but depends on the individual rectal compliance. According to the results given in the Table, however, the volume error is small and can be disregarded in the major pressure interval from $15 \mathrm{~cm}$ $\mathrm{H}_{2} \mathrm{O}$ upwards. A technically more sophisticated system for volume recording has recently been developed by Azpiroz and Malagelada, ${ }^{17}$ which creates an almost perfect isobaric condition by using a barostat, and this may be adopted to rectoanal motility studies.

We conclude that for clinical use reduction of preset pressure must be accounted for when large rectal volumes are obtained at low distension pressure. Moreover, body position is important as the pelvic hydrostatic counterpressure is increased in the supine position. Therefore the position of the patient must be defined to allow for interindividual and intra-individual comparison.

\section{ANAL MANOMETRY}

Various devices have been designed for recording of anal pressure since the first advanced system for experimental use was introduced in $1935 .{ }^{18}$ From a principal point of view there are two different types of anal recording devices: on one hand open tip catheters and miniature pressure transducers and on the other balloon systems. Open tip catheters and minitransducers are mainly used in detailed analysis 
of pressure profiles in the anal canal..$^{1922}$ The main advantage is that the point of measurement is well defined, but there is an influence of the axial orientation which may introduce errors in serial measurements.

The predominant system used for anal pressure recording is the balloon or cuff system, to which the present system should be referred. The most well known and often used is the tandem balloon device originally designed by Schuster. ${ }^{12}$ Several variations of this system are presently in use, containing one or two balloons, small or large balloons and cylindrical cuffs or spherical balloons. The present system uses a comparatively long cylindrical cuff consistent with a design previously used by others. ${ }^{8}$ From a theoretical point of view, a long cylindrical cuff inflated with a small amount of fluid that does not stretch the cuff membrane would record an average pressure from the part of the anal canal in which the cuff resides. The pull through analysis done in the present study supports this view and showed that a pressure plateau is obtained with only minor variations caused by changing the position in the anal canal. We also found that the pressure recorded during pull through was consistently higher than that recorded from the finebore open tip catheter, used for comparison. This observation is in agreement with earlier studies which show that the anal pressure record increases proportionally to the diameter of the probe. ${ }^{1123}$

Those in favour of the tandem system of balloons claim that internal sphincter activity can be distinguished from activity in the external anal sphincter because of the spatial displacement between the two muscles. ${ }^{679101222}$ Support for this claim by the simultaneous recording of EMG bursts and distal balloon pressure increase has been published. ${ }^{24}$ In the present method we choose to record external sphincter EMG and anal pressure, as generated in external and internal anal sphincter. The contribution of the striated sphincter is qualitatively reflected from the simultaneous EMG recording.

In the present investigation a significant drop in anal pressure was uniformly recorded the first minutes after introduction of the anal probe. This is an observation that has been given little attention previously, ${ }^{25}$ but appears to be of great importance for the reproducibility of anal pressure recordings, when probes of large diameters are used.

In summary we claim that the cylindrical cuff probe for anal pressure recording is insensitive to axial orientation and has a tolerance for longitudinal displacement amounting to $\pm 0.5 \mathrm{~cm}$. It records from the external and internal sphincter and the relative variation in external sphincter activity is disclosed by the EMG. Anal adaptation to the probe necessitates at least eight minutes of recording before relevant readings can be achieved. Access to the rectum through the lumen of the endotracheal tube is considered an advantage as is the disposable nature of the equipment.

\section{REPRESENTATIVE REGISTRATION}

As is shown in Figure 8, the rectoanal inhibitory reflex is readily elicited and visualised using the present method. The initial increase in EMG-activity corresponds to a shortlasting pressure increase preceding the inhibition, which is in concert with earlier observations. ${ }^{9}$ A possible source of error in the manometric diagnosis of Hirschsprung's disease is avoided by the present isobaric system. In patients with a megarectum inflation of standard increments of volume into the rectal balloon may fail to elicit the rectoanal reflex. This risk is obviated when the distension pressure is kept constant and the volume is allowed to vary as was previously stated. ${ }^{26}$

A shortlasting decrease of rectal volume which followed the initial volume expansion at rectal distension most likely represents a reflex contraction of the rectum. A reflex contraction has been observed earlier as a transient pressure increase on incremental rectal filling. ${ }^{1627}$ In our healthy subjects only minimal motility was seen after the initial contraction. This is in contrast with that found at distension of any other part of the small and large bowel (unpublished observations). A 'receptive relaxation' has been suggested to exist in the rectum ${ }^{2}$ and the absence of motor activity on prolonged distension may be an expression of rectal receptive relaxation. We believe that the present method is suitable for further studies on rectal motility and volume adaptation.

The study was supported by a grant from the Medical Society of Göteborg, the Medical Faculty, University of Göteborg and the Swedish Medical Research Council (MFR:03117). We gratefully acknowledge the expert technical assistance of Miss Lena Swenson.

\section{References}

1 Schuster MM. Motor action of the rectum and anal sphincters in continence and defecation. In: Code CF, ed. Handbook of physiology. Sec 6: Alimentary canal. Washington DC: American Physiological Society, 1968: 2121-46.

2 Fasth S, Hultén L, Nordgren S. Evidence for a dual pelvic nerve influence on large bowel motility in the cat. J Physiol 1980; 298: 156-69.

3 Jahnberg T, Martinson J, Hultén L, Fasth S. Dynamic gastric response to expansion before and after vagotomy. Scand J Gastroenterol 1975; 10: 593-8.

4 Martinson J. Studies on the afferent vagal control of the stomach. Acta Physiol Scand 1965; suppl: 65; 255: 1-24. 
5 Sundin T, Carlsson LA. Reconstruction of severed dorsal roots innervating the urinary bladder. An experimental study in cats. I. Studies on the normal afferent pathways in the pelvic and pudendal nerves. Scand $J$ Urol Nephrol 1972; 6: 176-84.

6 Aaronson I, Nixon HH. A clinical evaluation of anorectal pressure studies in the diagnosis of Hirschsprung's disease. Gut 1972; 13: 138-46.

7 Arhan P, Faverdin C, Thouvenot J. Ano-rectal motility in sick children. Scand J Gastroenterol 1972; 7: 309-14.

8 Frenckner B, v Euler C. Influence of pudendal block on the function of the anal sphincters. Gut 1975; 16: 482-9.

9 Ihre T. Studies on anal function in continent and incontinent patients. Scand J Gastroenterol 1974; suppl: 25; 18: $1-64$.

10 Meunier P, Mollard P, Jaubert de Beaujeu M. L'exploration manométrique de l'appareil anorectal de l'enfant: application aux megacolon. Pediatrie 1974; 29: 679-88.

11 Read MG, Read NW, Barber DC, Duthie HL. Effects of loperamide on anal sphincter function in patients complaining of chronic diarrhoea with fecal incontinence and urgency. Dig Dis Sci 1982; 27: 807-14.

12 Schuster MM, Hookman P, Hendrix TR, Mendeloff AI. Simultaneous manometric recording of internal and external anal sphincteric reflex. Bull Johns Hopkins Hosp 1965; 116: 79-88.

13 Kerremans R. Morphological and physiological aspects of anal continence and defecation. Bruxelles: Editions Arshia SA, 1969: 150.

14 Penninckx F. Morphological and physiological aspects of anal function. Leuven, Belgium: Thesis, 1981: 51-65.

15 Hightower NC, Code CF, Maher FT. A method for the study of gastro-intestinal motor activity in human beings. Proc Staff Meetings Mayo Clinic 1949; 24: 453-62.
16 Arhan P, Faverdin C, Persoz B, Devroede G, Dubois $F$, Pellerin D. Relationship between viscoelastic properties of the rectum and anal pressure in man. J Appl Physiol 1976; 41: 677-82.

17 Azpiroz F, Malagelada J-R. Physiological variations in canine gastric tone measured by an electronic barostat. Am J Physiol 1985; 248: 229-37.

18 Denny-Brown D, Graeme Robertson E. An investigation of the nervous control of defecation. Brain 1935; 58: 256-310.

19 Duthie HL, Bennett RC. The relation of sensation in the anal canal to the functional anal sphincter: a possible factor in anal continence. Gut 1963; 4: 179-82.

20 Hill JR, Kelley ML, Schlegel JF, Code CF. Pressure profile of the rectum and anus of healthy persons. Dis Colon Rectum 1960; 19: 203-9.

21 Howard ER, Nixon HH. Internal anal sphincter. Arch Dis Child 1968; 43: 569.

22 Phillips SF, Edwards AN. Some aspects of anal continence and defaecation. Gut 1965; 6: 396-406.

23 Gutierrez JG, Oliai A, Chey WY. Manometric profile of the internal anal sphincter in man. Gastroenterology 1975; 68: 407.

24 Schnaufer L, Talbert JL, Haller JA, Reid NCRW, Tobon F, Schuster MM. Differential sphincteric studies in the diagnosis of ano-rectal disorders of childhood. J Pediatr Surg 1967; 2: 538-43.

25 Duthie HL, Kwong NK, Brown B. Adaptability of the anal canal to distension. Br J Surg 1970; 57: 388.

26 Hedlund H, Fasth S, Hultén L, Nordgren S. A modified method for anorectal manometry for diagnosis of functional disorders of defecation. Svensk Kirurgi 1981; 34: 75 .

27 Bárány F. Pressure variations in the rectum and ileum during experimentally induced urgency of defecation. Acta Med Scand 1966; 41: 455-61. 